\title{
Developmental and speech delay due to s0X5 deficiency
}

INSERM

\section{Source}

INSERM. (1999). Orphanet: an online rare disease and orphan drug data base.

Developmental and speech delay due to SOX5 deficiency. ORPHA:313892

Developmental and speech delay due to SOX5 deficiency is a rare genetic syndromic intellectual disability characterized by mild to severe global developmental delay, intellectual disability and behavioral abnormalities, hypotonia, strabismus, optic nerve hypoplasia and mild facial dysmorphic features (down slanting palpebral fissures, frontal bossing, crowded teeth, auricular abnormalities and prominent philtral ridges). Other associated clinical features may include seizures and skeletal anomalies (kyphosis/scoliosis, pectus deformities). 